\title{
Complementary Feeding Status of Children Residing in Urban Slum of East Delhi
}

\author{
Shyambhavee Behera ${ }^{1}$, Khan Amir Maroof ${ }^{2, *}$, Pradeep Kumar Tiwari ${ }^{2}$
}

\section{Shyambhavee Behera', Khan Amir Maroof ${ }^{2, *}$, Pradeep Kumar Tiwari² 'Department of Community Medicine, Atal Bihari Vajpayee Institute of Medical Sciences and Dr RML Hospital, New Delhi, INDIA.}

${ }^{2}$ Department of Community Medicine, University College of Medical Sciences, Delhi, INDIA.

\section{Correspondence}

\section{Dr. Khan Amir Maroof}

Associate Professor, Department of

Community Medicine, University College of Medical Sciences, Delhi-110095, INDIA.

Mobile no: +919711914361

Email: khanamirmaroof@yahoo.com

History

- Submission Date: 24-05-2020

- Revised Date: 16-07-2020

- Accepted Date: 20-08-2020

DOI : 10.5530/ijmedph.2020.3.27

Article Available online

http://www.ijmedph.org/v10/i3

\section{Copyright}

(C) 2020 Phcog.Net. This is an openaccess article distributed under the terms of the Creative Commons Attribution 4.0 International license.

\begin{abstract}
Background: Feeding practices both in terms of quality as well as quantity is of great importance in the initial years of life for the optimal growth especially the "critical window period". Urban slum dwellers are at higher risk of poor child feeding status. The study aims to assess the IYCF indicators related to complementary feeding in an urban slum of East Delhi and to explore its association with the socio-demographic factors. Methodology: A cross-sectional study was conducted in an urban slum of Sunder Nagari in East Delhi. One hundered and eighty one children between 6-24 months of age were included in the study. The infant and young child feeding (IYCF) status data was collected using pretested and pre-validated questionnaire adapted from the standard WHO-IYCF questionnaire. Socio-demographic characteristics were also recorded. Chi-square tests were applied to explore the association of socio-demographic variables with IYCF status. Results: Early initiation of breastfeeding was practiced in around half of the children. Minimum Dietary Diversity (MDD), Minimum Meal Frequency (MMF) and Minimum Acceptable Diet (MAD) was found to be $17.7 \%, 69.1 \%$ and $16.6 \%$, respectively. These complementary feeding indicators were found to be better $(p<0.05)$ among higher age group children, mothers with higher level of education and middle socio-economic class in comparison to lower socioeconomic section of the study population. Conclusion: Infant and young child feeding practices were found to be poor in the present study. More impetus is needed to promote IYCF practices in urban slums.

Key words: IYCF indicators, Complementary feeding, Minimum Dietary Diversity, Minimum Meal Frequency, Minimum Acceptable Diet.
\end{abstract}

\section{BACKGROUND}

Adequate nutrition in the early childhood is the key towards healthy and prosperous adult life. Optimal breastfeeding during the early childhood has protective effect on infections including diarrhoea and respiratory infections. ${ }^{1}$ Nearly 2.4 million deaths among under 5 children can be averted by effective nutritional interventions including breastfeeding, complementary feeding and other micronutrient supplementation like zinc and vitamin A. ${ }^{2}$ Feeding practices both in terms of quality as well as quantity is of great importance, as stunting has been reported even in presence of optimum breast feeding practices, due to lack of quality complementary feeds during later months of this "critical window" period. ${ }^{3}$

As reported by the National Family Health Survey (NFHS), national level values for the IYCF indicators have improved from NFHS 3 to NFHS $4 .{ }^{4} \mathrm{~A}$ major lag still exists in reaching the Sustainable Development Goal 2 to achieve Zero Hunger. ${ }^{5}$ Children in urban slums are at an increased risk of under nutrition but data from urban slums are lacking. Most of the published studies have focused on breastfeeding and studies on complementary feeding are limited.

The study aims to assess the IYCF indicators related to complementary feeding in an urban slum of East
Delhi and to explore its association with the sociodemographic factors.

\section{METHODOLOGY}

A cross-sectional study was conducted in an urbanslum of Sundar Nagari in East Delhi from February 2018 to March, 2018. Considering the estimated prevalence of Minimum Meal Frequency as 48.6\%, ${ }^{6}$ for a confidence interval of $95 \%$ and $15 \%$ relative allowable error the required sample size of 181 was calculated using the following formula: $n=\left(\mathrm{Z}^{2} \times \mathrm{P}\right.$ $(1-P)) / \mathrm{e}^{2}$, where $\mathrm{Z}=$ value from standard normal distribution corresponding to desired confidence level $(\mathrm{Z}=1.96$ for $95 \% \mathrm{CI}), \mathrm{P}=$ prevalence, $\mathrm{e}=$ permissible error.

Children between the age group of 6 months to 24 months were included in the study. The population of Sundar nagari is around 80,000 and the majority of the families belong to middle or lower socioeconomic status. Consecutive sampling was used to collect data by house to house survey from the mothers or primary caregivers of the eligible children. They were interviewed face to face, after obtaining informed consent. 


\section{Data collection tool}

The data was collected using pretested questionnaire based on standard WHO-IYCF questionnaire. The data collection tool was designed to collect 10 key WHO IYCF indicators. ${ }^{7}$ The questionnaire was divided into three sections namely, socio-demographic profile, breast feeding practices and complementary feeding practices.

Socio-demographic profile included, type of family, education and occupation of mother and socio-economic status of the family (calculated using Modified Kuppuswamy Scale). The WHO-IYCF indicators included 6 breast feeding related indicators (Early initiation of breast feeding, Continued breast feeding at 1 and 2 years age, age appropriate breast feeding and child ever breast fed) and 4 complementary feeding indictors (Introduction of solid, semi-solid soft foods, Minimum Meal Frequency (MMF), Minimal Dietary Diversity (MDD) and Minimum Adequate Diet (MAD)), that were calculated based on the standard method devised in WHO-IYCF guideline. Previous day recall method was used to calculate all the IYCF feeding indicators except "early initiation of breast feeding" and "child ever breast fed"?

\section{Data analysis}

The data collected was entered into computer-based spreadsheet and cleaned using MS-Excel and analysed using SPSS 20.0 (Statistical Package for Social Sciences version 20.0). The Complementary feeding indicators are presented as proportions, whereas the continuous variables such as age are presented as means and standard deviations. Chi-square test was used to test the statistical association of the complementary feeding indicators and the socio-demographic characteristics. $P$ value of less than 0.05 was considered as statistically significant.

\section{RESULTS}

Mean (SD) age of the study participants was 14 (5.13) months, with nearly $44.8 \%, 35.9 \%$ and $19.3 \%$ in $6-12,12-18$ and $18-24$ months age group, respectively. The study population had nearly equal distribution among both genders (50.3\% male and $49.7 \%$ female) and type of family (51.4\% Nuclear and $48.6 \%$ Joint). Out of 181 participants, $94.5 \%$ of the mothers of study participants were unemployed. 41 out of 181 participants were from middle socio-economic status.

\section{Infant and Young Child Feeding Practices (Table 1)}

Almost half of children had their first feed within $1 \mathrm{hr}$ of life. Although, nearly $15 \%$ of those infants received formula or animal milk or honey/ ghutti as their first feed. Almost $90 \%$ of the children were appropriately breastfed as per their age, where "age appropriate breastfeed for children 6 months to 23 months" is defined as "children who received breast milk, as well as solid, semi-solid or soft foods, during previous day." Continued breast feeding at 1 and 2 year of age was found in almost three fourth and half of the study participants, respectively.

Although age appropriate feeding was found in majority of the children, nearly half of the children were bottle fed. Only $17 \%$ of the children received their meal constituting 4 or more food group out of 7 food group, i.e., grains, roots and tubers, legume and nuts, dairy products, flesh foods, eggs, vitamin A rich fruits and vegetables and other fruits and vegetable (MDD). Figure 1 shows the distribution of food groups received by the children the previous day. MMF, defined as the children who received solid, semi-solid or soft foods minimum number of times the previous day (2, 3 and 4 times for breast fed 6-8 months, 9-23 month and non-breastfed 6-23-month children, respectively), was found in almost $70 \%$ of children. Children who had both MDD and MMF were known to have Minimum Acceptable Diet, as per WHO-IYCF definition, was seen in only $16 \%$ of children.
The association of complementary feeding indicators with certain socio-demographic characteristics is shown in Table 2. All the three Complementary feeding indicators including adequate MDD, MMF and $\mathrm{MAD}$, were significantly higher among the older age group children as compared to younger age group. Other significant socio-demographic factors were higher educational status of the mother and higher socioeconomic status of the family.

\section{DISCUSSION}

Under nutrition still affects majority of the children particularly belonging to the impoverished urban slums regions, leading to multiple morbidity and mortality in later ages ${ }^{8,9}$ Optimal feeding practices during

\section{Table 1: Infant and Young Child Feeding Indicators.}

\begin{tabular}{|c|c|c|c|}
\hline & & Frequency & Percentage \\
\hline $\begin{array}{l}\text { Early initiation of breast } \\
\text { feeding }(n=181)\end{array}$ & & 94 & 51.9 \\
\hline \multirow{4}{*}{$\begin{array}{l}\text { First feed given to the child } \\
\qquad(n=181)\end{array}$} & Breast Milk & 151 & 83.4 \\
\hline & Formula Milk & 19 & 10.5 \\
\hline & Honey / Ghutti & 4 & 2.2 \\
\hline & Animal Milk & 7 & 3.9 \\
\hline Ever Breast-feed $(n=181)$ & & 178 & 98.3 \\
\hline $\begin{array}{c}\text { Continued breast feeding till } 1 \\
\text { year of age }(n=35)^{*}\end{array}$ & & 26 & 74.3 \\
\hline $\begin{array}{c}\text { Continued breast feeding till } 2 \\
\text { year of age }(n=56)^{s}\end{array}$ & & 27 & 48.2 \\
\hline $\begin{array}{l}\text { Age appropriate breast feeding } \\
\qquad(n=181)\end{array}$ & & 163 & 90.1 \\
\hline $\begin{array}{l}\text { Introduction of solid and semi- } \\
\text { solid food }(n=28)^{¥}\end{array}$ & & 22 & 78.6 \\
\hline $\begin{array}{l}\text { Bottle feeding ever introduced } \\
\qquad(n=181)\end{array}$ & & 80 & 44.2 \\
\hline $\begin{array}{c}\text { Adequate Minimum Dietary } \\
\text { Diversity }(n=181)\end{array}$ & & 32 & 17.7 \\
\hline $\begin{array}{l}\text { Adequate Minimum Meal } \\
\text { Frequency }(n=181)\end{array}$ & & 125 & 69.1 \\
\hline $\begin{array}{c}\text { Adequate Minimum } \\
\text { Acceptable Diet }(n=181)\end{array}$ & & 30 & 16.6 \\
\hline
\end{tabular}

${ }^{*}$ Among children 12-15 months of age, \$Among children 20-23 months of age, ¥Among children 6-8 months of age

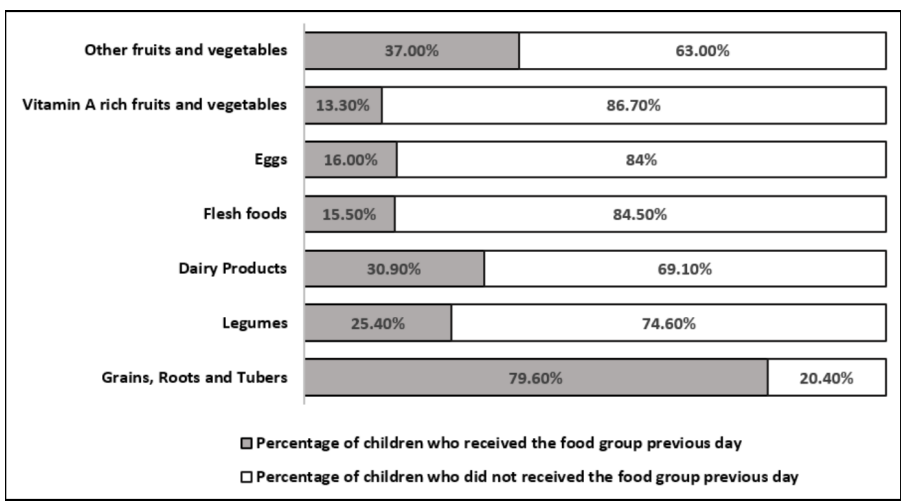

Figure 1: Distribution of food groups received by the children on previous day 
Table 2: Association of Minimum Dietary Diversity, Minimum Meal Frequency, Minimum Acceptable Diet with sociodemographic determinants among study participants $(n=181)$.

\begin{tabular}{|c|c|c|c|c|c|}
\hline & & $\begin{array}{l}\text { Frequency } \\
\text { (Percentage) }\end{array}$ & $\begin{array}{l}\text { Minimum Dietary } \\
\text { Diversity } \\
\text { [n (\%)] }\end{array}$ & $\begin{array}{l}\text { Minimum Meal } \\
\text { Frequency } \\
{[n(\%)]}\end{array}$ & $\begin{array}{c}\text { Minimum } \\
\text { Acceptable Diet } \\
{[\mathrm{n}(\%)]}\end{array}$ \\
\hline \multirow[t]{4}{*}{ Age Range } & 6-12 months & $81(44.8 \%)$ & $6(7.4 \%)$ & $50(61.7 \%)$ & $6(7.4 \%)$ \\
\hline & $12-18$ months & $65(35.9 \%)$ & $17(26.2 \%)$ & $44(67.7 \%)$ & $15(23.1 \%)$ \\
\hline & 18-24 months & $35(19.3 \%)$ & $9(25.7 \%)$ & $31(88.6 \%)$ & $9(25.7 \%)$ \\
\hline & $p$-value & & 0.005 & 0.016 & 0.012 \\
\hline \multirow[t]{3}{*}{ Gender } & Male & $91(50.3 \%)$ & $12(13.2 \%)$ & $59(64.8 \%)$ & $12(13.2 \%)$ \\
\hline & Female & $90(49.7 \%)$ & $20(22.2 \%)$ & $66(73.3 \%)$ & $18(20.0 \%)$ \\
\hline & $p$-value & & 0.111 & 0.216 & 0.218 \\
\hline \multirow[t]{3}{*}{ Religion } & Hindu & $116(64.1 \%)$ & $20(17.2 \%)$ & $82(70.7 \%)$ & $20(17.2 \%)$ \\
\hline & Muslim & 65 (35.9\%) & $12(18.5 \%)$ & $43(66.2 \%)$ & $10(15.4 \%)$ \\
\hline & $p$-value & & 0.836 & 0.527 & 0.747 \\
\hline \multirow[t]{3}{*}{ Type of Family } & Nuclear & $93(51.4 \%)$ & $14(15.1 \%)$ & $61(65.6 \%)$ & $13(14.0 \%)$ \\
\hline & Joint & $88(48.6 \%)$ & $18(20.5 \%)$ & $64(72.7 \%)$ & $17(19.3 \%)$ \\
\hline & $p$-value & & 0.341 & 0.299 & 0.334 \\
\hline \multirow{4}{*}{$\begin{array}{l}\text { Education status } \\
\text { of mother }\end{array}$} & Illiterate & $50(27.6 \%)$ & $5(10.0 \%)$ & $24(48 \%)$ & $4(8.0 \%)$ \\
\hline & $\begin{array}{c}\text { High School Certificate } \\
\text { or Below }\end{array}$ & $94(51.9 \%)$ & $16(17.0 \%)$ & $70(74.5 \%)$ & $15(16.0 \%)$ \\
\hline & $\begin{array}{l}\text { Intermediate or post high } \\
\text { school diploma above }\end{array}$ & $37(20.4 \%)$ & $11(29.7 \%)$ & $31(83.8 \%)$ & $11(29.7 \%)$ \\
\hline & $p$-value & & 0.05 & $<0.01$ & 0.02 \\
\hline \multirow{3}{*}{$\begin{array}{l}\text { Occupation of } \\
\text { mother }\end{array}$} & Unemployed & $171(94.5 \%)$ & $29(17.0 \%)$ & $116(67.8 \%)$ & $27(15.8 \%)$ \\
\hline & Employed & $10(5.5 \%)$ & $3(30.0 \%)$ & $9(90.0 \%)$ & $3(30.0 \%)$ \\
\hline & $p$-value & & $0.38^{\star}$ & $0.17^{\star}$ & $0.24^{\star}$ \\
\hline \multirow{3}{*}{$\begin{array}{l}\text { Socio-economic } \\
\text { Status }\end{array}$} & Middle Class & $41(22.7 \%)$ & $15(36.6 \%)$ & $34(82.9 \%)$ & $15(36.6 \%)$ \\
\hline & Lower Class & $140(77.3 \%)$ & $17(12.1 \%)$ & $91(65.5 \%)$ & $15(10.7 \%)$ \\
\hline & $p$-value & & $<0.01$ & 0.020 & $<0.01$ \\
\hline Total & & & $32(17.7 \%)$ & $125(69.1 \%)$ & $30(16.6 \%)$ \\
\hline
\end{tabular}

${ }^{*}$ As per Modified Kuppuswamy Scale *Fischer exact test

the initial developmental years of life forms the foundation towards healthy life.

Even though early initiation of breast feeding i.e. within $1 \mathrm{hr}$ of birth was found to be higher (52\%) in comparison to the National Family Health Survey- 4 (NFHS), Delhi (28\%). ${ }^{10}$ With almost $85 \%$ of the deliveries being conducted at institutions, such a figure still remains non-promising. Similar findings were observed by multiple studies conducted across the country. ${ }^{11,12}$ Reasons for delayed initiation of breast feeding could be lack of knowledge among new mothers, caesarean section deliveries or other prevalent cultural practices.

Continued breastfeeding till the age of 1 and 2 year was reported to be almost $75 \%$ and $50 \%$, respectively in the current study. A study by Chaudhary SR et al. ${ }^{13}$ in an urban slum of Ahmedabad reported only $30 \%$ of 12-23 months children who received breastfeed till 2 year of age, whereas almost similar findings as current study was reported by Khan et al. ${ }^{7}$ and Deshmukh et al. ${ }^{11}$ Longer duration of breastfeeding well beyond one year of age not only provides an additional source of energy along with other key nutrients, also carries multiple benefits to the lactating mother. ${ }^{14,15}$
Nearly $45 \%$ of the children were fed on bottle feed in the current study. Introduction of bottle feed among infants and young children, especially in coherence with poor hygiene practices makes the child more susceptible to risks of added infections. ${ }^{16,17}$ Also, early introduction of bottle feed is found to be associated with lack of suckling effort by the infant. ${ }^{17}$

Introduction of complementary feeds at 6 months of age forms a critical window period, with any delay leading to faltering growth and other nutritional deficiencies. Timely introduction of solid or semi-solid soft food was reported among 22 out of 28 children among the age group of 6 to 8 months of age. A similar study in the urban slums of Gujarat also reported timely initiation of complementary feed among $60 \%$ of the infants. $^{18}$

Minimum Dietary Diversity (MDD) was found to be adequate only among $17.7 \%$ of the study participants. Consumption from minimum 4 groups signifies high likelihood of consumption of at least one animalsource food and one fruit or vegetable with a staple food grain. MDD was found to be significantly associated with higher age group children, higher education level of the mother and higher socio-economic status. Similar association was reported in study by Solomon D et al. ${ }^{19}$ in 
Ethiopia. Although, MDD score was found to be much higher in their study. Chaudhary SR et al. ${ }^{13}$ reported similar MDD score of nearly $15 \%$ in an urban slum of Ahmedabad. Higher percentage of MDD was also reported by Khan et al. in Delhi ${ }^{7}$ and Deshmukh U et al. in Maharashtra. ${ }^{11}$

Age appropriate Minimum Meal Frequency (MMF) was observed in almost $70 \%$ of the study participants, inclusive of both breast fed and non-breastfed children. Similar findings were also reported by studies done in other geographic regions of the world. ${ }^{11,13,19,20}$ Although study by Khan et al. in Delhi reported lower meal frequency. ${ }^{7}$ Different regional and cultural beliefs, practices and variable socio-demographic profile could be the reason behind disparity in findings with in the studies. A similar association of MMF among higher age group was also reported by Tegegne $\mathrm{M}$ et al. ${ }^{20}$ Thus, signifying higher diversity as well as frequency with increasing age of the children. High economic stability and purchasing power could be the reason behind higher MDD and MMF scores among higher socio-economic section of participants.

Our study reported only $17 \%$ of the infants and children receiving a Minimum Acceptable Diet (MAD), similar to the findings of other related studies conducted in the country. ${ }^{7,11,13,18} \mathrm{~A}$ study by Mulat E. et al. report even less frequency of MAD in west Ethiopia. ${ }^{21}$ Higher education status of the mother was found to be a significantly associated with higher MAD, as also reported by Mulat E et al. ${ }^{21}$

The study was conducted in a single urban slum of Delhi and therefore its external validity is limited. The association between the complementary feeding indicators and certain socio-demographic indicators is exploratory as the sample sizes and study design was primarily for a descriptive study and not a comparative study.

\section{CONCLUSION}

The IYCF indicators related to complementary feeding were found to be poor in the present study. More efforts focused on children living in urban slums is needed to improve their IYCF status.

\section{ACKNOWLEDGEMENT}

A vote of thanks to all the MBBS undergraduate students who were part of the project.

\section{CONFLICT OF INTEREST}

The authors declare no Conflict of interest.

\section{ABBREVIATIONS}

CI: Confidence Interval; IYCF: Infant and Young Child Feeding; MAD: Minimum Acceptable Diet; MDD: Minimum Dietary Diversity; MMF: Minimum Meal Frequency; NFHS: National Family Health Survey; WHO: World Health Organization.

\section{REFERENCES}

1. Horta BL, Victora CG, World Health Organization. Short-term effects of breastfeeding: A systematic review on the benefits of breastfeeding on diarrhoea and pneumonia mortality. World Health Organization. 2013. Available from: https://apps.who.int/iris/bitstream/handle/10665/95585/9789241506120_ eng.pdf? sequence $=1$ \&isAllowed $=y$

2. Jones G, Steketee RW, Black RE, Bhutta ZA, Morris SS. Bellagio Child Survival Study Group. How many child deaths can we prevent this year?. The Lancet. 2003;362(9377):65-71.

3. Nutrition. UNICEF. Complementary Feeding. 2020. Available from: https:// www.unicef.org/nutrition/index_24826.html.

4. India. Ministry of Health and Family Welfare State Fact Sheet. 2017. [cited Apr 4, 2017]. Available from: http://rchiips.org/NFHS/pdf/NFHS4/India.pdf

5. Sustainable Development Goals. United Nations. Goal 2: Zero Hunger. 2020. Available form: https://www.un.org/sustainabledevelopment/hunger/

6. Khan AM, Kayina P, Agrawal P, Gupta A, Kannan AT. A study on infant and youngchild feeding practices among mothers attending an urban health centre in East Delhi. Indian J of Public Health. 2012;56(4):301-4.

7. Nutrition. World Health Organization, Geneva Indicators for assessing infant and young child feeding practices. 2020. [cited April 30,2020]. Available from: https://apps.who.int/iris/bitstream/handle/10665/44306/9789241599290_eng. pdf?ua $=1$

8. Tomkins A. Malnutrition, morbidity and mortality in children and their mothers. Proceedings of the Nutrition Society. 2000;59(1):135-46.

9. Rice AL, Sacco L, Hyder A, Black RE. Malnutrition as an underlying cause of childhood deaths associated with infectious diseases in developing countries. Bulletin of the World Health Organization. 2000;78(10):1207-21.

10. Delhi N. Ministry of Health and Family Welfare State Fact Sheet. 2017. [Internet] [cited Apr 4, 2017]. Available from: http://rchiips.org/NFHS/pdf/NFHS4/DL_ FactSheet.pdf

11. Deshmukh U, Thomas T, Swaminathan S, Kurpad A. Breastfeeding Practices and Dietary Diversity among Infants and Young Children in Rural and UrbanSlum Populations in India: An Observational Study. International Journal of Child Health and Nutrition. 2018;7(4):175-83.

12. Bhagwat B, Nooyi SC, Krishnareddy DH, Murthy SN. Association of Practices Regarding Infant and Young Child Feeding with Anthropometry Measurements Among an Urban Population in Karnataka, India. Cureus. 2019;11(3):e4346.

13. Chaudhary SR, Govil S, Lala MK, Yagnik HB. Infant and Young Child Feeding Index and its association with nutritional status: A cross-sectional study of urban slums of Ahmedabad. J Family Community Med. 2018;25(2):88-94.

14. e-Library of Evidence for Nutrition Actions (eLENA). World Health Organization, Geneva. 2020. [cited April 10, 2020]. Continued breastfeeding for healthy growth and development of children. Available from: https://www.who.int/ elena/titles/continued_breastfeeding/en/

15. Infant and young child feeding. World Health Organization, Geneva. 2020. [cited April 20, 2020]. Key facts. Available from: https://www.who.int/news-room/factsheets/detail/infant-and-young-child-feeding

16. Gribble KD, Hausman BL. Milk sharing and formula feeding: Infant feeding risks in comparative perspective?. The Australasian Medical Journal. 2012;5(5):27583.

17. Infant and young child feeding. World Health Organization. 2020. [cited April 24, 2020]. Model Chapter for textbooks for medical students and allied health professionals. Available from: https://www.who.int/nutrition/publications/ infantfeeding/9789241597494.pdf

18. Rajesh D, Bhavana D. A study on infant feeding practices in the urban slums: a cross sectional study. Int J Contemp Pediatr. 2016;3(2):350-4.

19. Solomon D, Aderaw Z, Tegegne TK. Minimum dietary diversity and associated factors among children aged 6-23 months in Addis Ababa, Ethiopia. International Journal for Equity in Health. 2017;16(1):181.

20. Tegegne M, Sileshi S, Benti T, Teshome M, Woldie H. Factors associated with minimal meal frequency and dietary diversity practices among infants and young children in the predominantly agrarian society of Bale zone, Southeast Ethiopia: A community based cross sectional study. Archives of Public Health. 2017;75(1):53.

21. Mulat $\mathrm{E}$, Alem G, Woyraw W, Temesgen $\mathrm{H}$. Uptake of minimum acceptable diet among children aged 6-23 months in orthodox religion followers during fasting season in rural area, DEMBECHA, north West Ethiopia. BMC Nutrition. 2019;5(1):18. 